\title{
Are anemia and blood group types related to Japanese encephalitis and dengue?
}

Introduction: Dengue and Japanese encephalitis (JE) are flaviviruses causing significant morbidity and mortality worldwide. Previous studies had found an association between dengue infection and particular blood group antigen and also the susceptibility to aplastic anemia by dengue. Aims and Objective: The present study was conducted to find any association between dengue and JE immunoglobulin G ( $\mathrm{lgG}$ ) antibody with blood group antigen or anemia. Methodology: The study was conducted in 2 slums of Delhi in 2013 in the interepidemic period. $5 \mathrm{~mL}$ blood from 239 samples were taken and processed for lgG levels of dengue and JE and rest used to test hemoglobin and blood group. Results and Discussion: No association has been found between blood group types and dengue IgG antibody positivity $(P=0.42)$ or JE IgG antibody positivity $(P=0.148)$. Nor did anemia established any association with dengue $(P=0.185)$ or JE IgG antibody $(P=0.277)$. IgG status of dengue and JE could be used as proxy markers of any past subclinical infection (includes clinically manifested cases also). Further studies in large settings and other areas could be done to validate the results. This was the first study of its kind in such settings.

Key words: Anemia, dengue, ELISA, Japanese encephalitis

\section{INTRODUCTION}

Shantanu Sharma, Vimal Kumar Gupta, Ajay Kumar Jain', Anita Chakravarti $^{2}$

Departments of Community Medicine, ${ }^{1}$ Physiology and ${ }^{2}$ Microbiology, MAMC, New Delhi,

India

Address for the Correspondence: Shantanu Sharma, Department of Community Medicine, MAMC, New Delhi, India. E-mail: shantanusharma145@ gmail.com

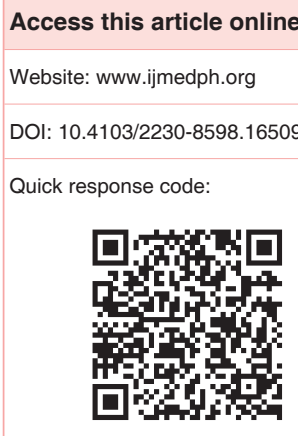

Dengue has become a major public health problem nationally as well as international with increasing geographic distribution, transition from epidemic transmission with long interepidemic periods to endemic transmission with seasonal fluctuations. There has been an increase in morbidity as well as mortality due to dengue with South East Asian countries reporting 2.34 million cases alone from 2003 to 2012 and 1980 deaths in 2010. ${ }^{[1]}$ India, an endemic country for dengue reported 75,454 cases and 167 deaths in 2013. ${ }^{[2]}$ Dengue being even more threatening due to the absence of any vaccine in the market, nonavailability of specific treatment and absence of cross-protective immunity against other serotypes.

Japanese encephalitis (JE) another flavivirus related to dengue is a major cause of mortality in both children and elderly. 24 countries in the WHO South-East Asia and Western Pacific regions have endemic JE transmission, exposing more than 3 billion people to risk of infection. Nearly 68,000 clinical cases of JE occur globally each year, with up to 20,400 deaths due to JEs. ${ }^{[3]}$ India too witness JE epidemics with certain states endemic for it like Uttar Pradesh, Bihar, Assam, etc.

The ABO blood group system is a part of the immune system of our body with different blood group types altering the susceptibility to various infections in the body. In a study by Kalayanarooj et al., 2007 it was found that ABO blood-group frequencies were similar in primary versus secondary dengue virus infections. However, in the secondary infection, individuals with blood group AB were likely to have dengue hemorrhagic fever grade 3 than either grade 1 and 2 combined. ${ }^{[4]}$

Role of presence of antibodies against infections or infections per se on hemoglobin status of individuals has not been talked much except for a study done in Vietnam published in 2005 where its association with malaria (odds ratio $=2.48$ ) was reported. ${ }^{[5]}$ With the current lacunae in existing knowledge, present study was done to find out if any particular blood group affected dengue or JE immunoglobulin G (IgG) status of an individual with respect to same environmental condition and does dengue or JE IgG status had any association with hemoglobin status for an individual. 


\section{Aims of the study}

To study for any association between dengue and JE IgG status of an individual with his/her blood group type or hemoglobin $(\mathrm{Hb})$ value.

\section{MATERIALS AND METHODS}

It was a community-based cross-sectional study conducted for a period of 12 months from January 2013 to December 2013. The samples were taken in the inter-epidemic period of dengue and JE. The study was carried out in Delhi which is located on $28.38^{\circ}$ north latitude and $77.13^{\circ}$ East Longitude. Mean annual temperature in Delhi is $25^{\circ} \mathrm{C}$. There are 3 major months of rainfall in Delhi as July, August, and September. ${ }^{[6]}$ The study was conducted in two urban areas of central Delhi which included Balmiki Basti (urban slum located near Feroz shah Kotla in the central district of Delhi) and Delhi Gate (urban slum in the central district of Delhi). These 2 areas were selected as they were being catered by the Department Of Community Medicine, MAMC, New Delhi. All males and females aged 20-60 years old residing in above-mentioned areas more than a year constituted the study population. A total of 239 samples were taken from the two area mentioned above. The adults taken from Delhi Gate were 204 and from Balmiki Basti 35. 100 households were taken from Delhi Gate and 25 from Balmiki Basti according to an average 2 adults per household. The houses were selected systematically. Every $14^{\text {th }}$ household was selected from Delhi Gate and every $10^{\text {th }}$ from Balmiki Basti. The adults were provided the description of the project, an informed consent forms, and questionnaires. If willing to participate then, they were asked to sign the informed consent form. A unique identification number was given to each subject enrolled in the study and was recorded in all study documents (informed consent form, data collection tools, the blood sample, and sera samples). Subject number comprised of five numeric digits: First two digits corresponded to the study site and the other three digits to the chronological order of enrollment for a study site. For the site "Balmiki Basti" - code was 01 and for "Delhi Gate" 02. For instance, the first subject enrolled in Balmiki Basti center was identified with the subject number $=01001$, and the fifth subject at Delhi Gate center $=02005$.

Information regarding the reasons why some subjects refused to participate in the study, upon proposal by us, was documented in a form called "refusal log". The geographic position reference and reason of refusal were recorded. The recording of this information was done to assess the representativeness of the study population sample. No code was assigned to those people refusing participation. The subjects were informed that they had the right to withdraw themselves from the study at any time. On refusal, they were asked for the reason. A total of 16 subjects refused to participate. The most common reason was fear of the needle used for collection of sample $(62.5 \%)$. Fifteen percent of the participants replied that they were not interested in the study while $22.5 \%$ never had dengue, so no perceived need of participating in the study and the fact that they already had blood investigation done. Venous sample was taken from the subject of about $5 \mathrm{ml}$ out of which $4 \mathrm{ml}$ was taken in a plain vacutainer for JE and dengue IgG testing and $1 \mathrm{ml}$ in hemogram vial for hemoglobin and blood group testing. Each vacutainer tube was identified by a label with the subject identification number and the date of sampling. The sample processing was done according to ELISA kit manufacturer's guidelines (Pan Bio. E-DEN01G. DENGUE IgG Indirect ELISA. France: EN; 2010). Hemocue Hb 301 system was used for $\mathrm{Hb}$ estimation.

\section{Statistical analysis}

The data were entered in MS-Excel and analyzed by using SPSS software version 17 (IBM statistics). Qualitative data were expressed in percentages with 95\% confidence interval. Quantitative data were expressed in mean \pm standard deviation (SD). Chi-square test/Fishers' exact test was used for qualitative variables. Cross tabulation was done to assess the relationship between dependent and independent variables. " $P<0.05$ " was considered significant.

\section{Ethical considerations}

The objective and procedure of the study was explained to the participants. Written informed consent was taken from the study subjects. The option to opt out of the study was kept open without any clause. The data were kept confidential and was used for research purpose only. The participants were given health education about mosquito-borne diseases and use of personal protective measures. The study was approved by Institutional Ethical Committee of the College (Maulana Azad Medical College).

\section{RESULTS}

\section{Sociodemographic characteristics of the study population}

A total of $49(20.5 \%)$ adults from Balmiki Basti and 190 from Delhi Gate were enrolled in the study. There were 82 males and 157 females from the two areas. Young adults constituted a major chunk $(35.5 \%)$ of the total study population whereas least representation was by adults of 50-60 years. In Balmiki Basti, males and females were comparable in number whereas in Delhi Gate females were proportionately higher. Mean age of study participants was $37 \pm 14.3$ years (mean $\pm \mathrm{SD}$ ) in the two areas. A total of $15(6.2 \%)$ participants were unemployed. Among unemployed participants, $76.2 \%$ were housewives. Overall mean number of family members per family were $6 \pm 2$ (mean \pm SD) and mean monthly income per family was around Rs. $12460 \pm 7040$ (mean \pm SD). Mean Hb concentration of participants was $12.4 \pm 2 \mathrm{~g} / \mathrm{dL}$ (mean $\pm \mathrm{SD}$ ). Though the range of $\mathrm{Hb}$ concentration varied from a minimum of $7.0 \mathrm{~g} / \mathrm{dL}$ to $17.30 \mathrm{~g} / \mathrm{dL}$, but none of the participants reported any symptoms related to anemia or polycythemia. Mean hemoglobin concentration of males is $13.42 \mathrm{~g} / \mathrm{dL} \pm 1.8$ (mean $\pm \mathrm{SD}$ ) and females is $11.9 \mathrm{~g} / \mathrm{dL} \pm 1.8$ (mean $\pm \mathrm{SD})(P=0.00$ ). Majorly, $93(38.9 \%)$ participants in the study had blood group O while $64(26.8 \%)$ had B, 55 (23.01\%) had A and the rest 27 (11.3\%) had AB blood group. Rh positive antigen was present in $220(92 \%)$ subjects. Prevalence of dengue $\mathrm{IgG}$ positivity was similar among both anemic (44.1) and 
nonanemic $(55.9 \%)(P=0.185)$ [Table 1]. Maximum seropositivity was found among the participants with O blood group (89.2\%) followed by subjects with blood group B (85.9\%). No significant association of any blood group type with dengue $\operatorname{IgG}$ positivity $(P=0.420)$ or $J E$ positivity status was found $(P=0.148)$ [Table 2]. JE IgG status was not statistically different between anemic and nonanemic $(P=0.277)$. Mean dengue $\operatorname{IgG}(P=0.928)$ and JE $\operatorname{IgG}$ $(P=0.331)$ values were similar in all blood group types [Table 3]. Mean Hb levels didn't differ among dengue IgG positive $(P=0.372)$ or JE IgG positive $(P=0.40)$ categories.

\section{DISCUSSION}

\section{Sociodemographic profile of study participants}

Participants from both the areas were of age 20-60 years. Therefore, a group of adults was selected for convenience to avoid sampling from children and low prevalence of antibody levels among geriatrics. The mean age of participants is also approximately same as the mean of the maximum and minimum age limits of study participants in the eligibility criteria. Female:male ratio in the study was 1.91 which is far above the sex ratio in Delhi ${ }^{[6]}$ that is, 0.867 . The probable cause for such a difference could be the time to approach subjects or the family visits. Since the visits used to be in the afternoon and the commonly available person in the home used to be females being housewives wherein males were often out due to job.

\section{Association of dengue/Japanese encephalitis with anemia or blood groups}

No significant association of anemia or mean $\mathrm{Hb}$ levels with dengue or JE antibody positivity or their mean levels was found. No association has been found between blood group types and dengue IgG antibody positivity $(P=0.42)$. In a study by Siripen Kalanarooj in Thailand, it was found that four blood groups had similar susceptibility to severe disease - that is, to DHF3 - and no correlation between blood group and disease severity was seen. In contrast, among patients with secondary dengue-virus infection, blood group AB's association with DHF3 was similar to both its association with DF $(\mathrm{OR}=0.119)$ and its association with DHF1 and DHF2 combined (OR $=0.097$ ). However, no comment on the association of $\operatorname{IgG}$ status with blood group status was made. Though the research on this topic has not been done much, but there are evidences of blood group association with other infections. Blood group antigens have been found linked to many infections as a risk factor like in recurrent urinary tract infections in women ${ }^{[7]}$ and Helicobacter pylori attachment to gastric mucosa ${ }^{[8]}$ and as protective factor against GGI genotype norovirus infection ${ }^{[9]}$ and Plasmodium vivax infection in blacks. ${ }^{[10]}$

Dengue could induce aplastic anemia through direct bone marrow invasion, ${ }^{[1]}$ infect hematopoietic cells and alter their proliferative capacity. ${ }^{[12]}$ Dengue, as evidenced from these studies, could predispose to anemia, but the current study failed to find any such association.

Blood group being a part of the immune system could make individuals susceptible to certain infections. Dengue and JE at

\begin{tabular}{|c|c|c|c|c|c|}
\hline \multirow{2}{*}{$\begin{array}{l}\text { Blood } \\
\text { parameters }\end{array}$} & \multicolumn{3}{|c|}{ Dengue IgG status } & \multirow{2}{*}{$\begin{array}{c}\text { Total } \\
n=239\end{array}$} & \multirow[t]{2}{*}{$P^{*}$} \\
\hline & $\begin{array}{c}\text { Negative } \\
(n=32) \\
n(\%)\end{array}$ & $\begin{array}{c}\text { Equivocal } \\
(n=3) \\
n(\%)\end{array}$ & $\begin{array}{c}\text { Positive } \\
(n=204) \\
n(\%)\end{array}$ & & \\
\hline Anemia & & & & & 0.185 \\
\hline Anemic & $17(53.1)$ & 0 & $90(44.1)$ & 107 & \\
\hline Non anemic & $15(64.9)$ & $3(100)$ & $114(55.9)$ & 132 & \\
\hline Blood group & & & & & 0.420 \\
\hline A & $11(20)$ & 0 & $44(80)$ & 55 & \\
\hline$B$ & $8(12.5)$ & $1(1.6)$ & $55(85.9)$ & 64 & \\
\hline$A B$ & $5(18.5)$ & 0 & $22(81.5)$ & 27 & \\
\hline $\mathrm{O}$ & $8(8.6)$ & $2(2.2)$ & $83(89.2)$ & 93 & \\
\hline
\end{tabular}

*In cells with expected cell count less than 5 , Fisher exact test was used

\begin{tabular}{|c|c|c|c|c|c|}
\hline \multirow{2}{*}{$\begin{array}{l}\text { Blood } \\
\text { parameters }\end{array}$} & \multicolumn{3}{|c|}{ JE IgG antibody } & \multirow{2}{*}{$\begin{array}{c}\text { Total } \\
239\end{array}$} & \multirow[t]{2}{*}{$P$} \\
\hline & $\begin{array}{c}\text { Negative } \\
(n=76) \\
n(\%)\end{array}$ & $\begin{array}{c}\text { Equivocal } \\
(n=110) \\
n(\%)\end{array}$ & $\begin{array}{c}\text { Positive } \\
(n=53) \\
n(\%)\end{array}$ & & \\
\hline Blood group & & & & & 0.148 \\
\hline A & $14(25.5)$ & $31(56.4)$ & $10(18.2)$ & 55 & \\
\hline B & $17(26.6)$ & $34(53.1)$ & $13(20.3)$ & 64 & \\
\hline$A B$ & $11(40)$. & 7 (25.9) & $9(33.3)$ & 27 & \\
\hline $\mathrm{O}$ & $34(36.6)$ & $38(40.9)$ & $21(22.6)$ & 93 & \\
\hline Anemia & & & & & 0.277 \\
\hline Anemic & $38(35.5)$ & $50(46.7)$ & $90(17.8)$ & 178 & \\
\hline Non anemic & $38(28.8)$ & $60(45.5)$ & $34(25.8)$ & 132 & \\
\hline
\end{tabular}

JE = Japanese encephalitis

\begin{tabular}{lcccc}
\multicolumn{4}{l}{$\begin{array}{l}\text { Table 3: Seropositivity of mean JE and mean } \\
\text { dengue antibody levels with variables }\end{array}$} \\
$\begin{array}{l}\text { Blood } \\
\text { parameters }\end{array}$ & $\begin{array}{l}\text { Mean JE } \\
\text { OD value }\end{array}$ & $\boldsymbol{P}$ & $\begin{array}{c}\text { Mean dengue } \\
\text { OD value }\end{array}$ & $\boldsymbol{P}$ \\
\hline Anemia & & 0.221 & & 0.25 \\
Anemic & $3.51 \pm 2.61$ & & $1.57 \pm 0.62$ & \\
Non anemic & $3.94 \pm 2.76$ & & $1.66 \pm 0.51$ & \\
Blood groups & & 0.928 & & \\
A & $3.59 \pm 2.33$ & & $1.52 \pm 0.671$ & 0.331 \\
B & $3.71 \pm 2.47$ & & $1.65 \pm 0.55$ & \\
AB & $4.01 \pm 3.21$ & & $1.55 \pm 0.62$ & \\
O & $3.78 \pm 2.91$ & & $1.68 \pm 0.488$ & \\
\hline
\end{tabular}

$\mathrm{JE}=$ Japanese encephalitis

most times present with mild symptoms and subside within a week being unrecognized. IgG status of dengue and JE could be used as proxy markers of any past subclinical infection (includes clinically manifested also). Presence of higher IgG titers in certain blood group types could be an inference in the way that blood group might be a risk factor for severe infections. However, the present study didn't generate any such hypothesis. Nor did this study revealed any association of Igs on B cell with $\mathrm{Hb}$ in RBC. Interaction between Igs on B cells and blood group antigens on RBCs if any, as concluded in a study, could further be tested with larger sample size and in other settings. 
Limitations of the study were the unequal representation of males in the study population. Study was conducted in Delhi and that in urban slums which cannot be extrapolated to the rest of the population which are different in geographic location, environment, and dengue or JE prevalence.

\section{REFERENCES}

1. World Health Organization. Dengue and Dengue Haemorrhagic Fever; 2008 May 20. [factsheet117]. Available from: http://www. who.int/mediacentre/factsheets/fs117/en/. [Last accessed on 2013 Sep 25].

2. National Vector Borne Disease Control Programme, Director General Health Services, Ministry of Health and Family Welfare. Available from: http://www.nvbdcp.gov.in. [Last accessed on 2014 Apr 12].

3. Fact sheet No 386: Japanese encephalitis. World Health Organization; 12 March 2014. Available from http://www.searo.who.int/thailand/ factsheets/fs0011/en/. [Last cited on 2014 Apr 02].

4. Kalayanarooj S, Gibbons RV, Vaughn D, Green S, Nisalak A, Jarman RG, et al. Blood group $A B$ is associated with increased risk for severe dengue disease in secondary infections. $J$ Infect Dis 2007;195:1014-7.

5. Le Hung Q, de Vries PJ, Giao PT, Binh TQ, Nam NV, Kager PA. Anemia, malaria and hookworm infections in a Vietnamese ethnic minority. Southeast Asian J Trop Med Public Health 2005;36:816-21.
6. Directorate of Economics and Statistics. Statistical abstract of Delhi 2012 Govt of NCT, Delhi; 2012.

7. Sheinfeld J, Schaeffer AJ, Cordon-Cardo C, Rogatko A, Fair WR. Association of the Lewis blood-group phenotype with recurrent urinary tract infections in women. N Engl J Med 1989;320:773-7.

8. Boren T, Falk P, Roth KA, Larson G, Normark S. Attachment of Helicobacter pylori to human gastric epithelium mediated by blood group antigens. Sci Mag 1993;262:1892-5.

9. Rockx BH, Vennema H, Hoebe CJ, Duizer E, Koopmans MP. Association of histo-blood group antigens and susceptibility to norovirus infections. J Infect Dis 2005;191:749-54.

10. Miller LH, Mason SJ, Clyde DF, McGinniss MH. The resistance factor to Plasmodium vivax in blacks. The Duffy-blood-group genotype, FyFy. N Engl J Med 1976;295:302-4.

11. Albuquerque PL, Júnior GBS, Diógenes SS, Silva HF. Dengue and aplastic anemia-A rare association. Travel medicine and infectious disease 2009;7:118-20.

12. Nakao S, Lai CJ, Young NS. Dengue virus, a flavivirus, propagates in human bone marrow progenitors and hematopoietic cell lines. Blood 1989;74:1235-40

How to cite this article: Sharma S, Gupta VK, Jain AK, Chakravart A. Are anemia and blood group types related to Japanese encephalitis and dengue?. Int J Med Public Health 2015;5:328-31.

Source of Support: Nil, Conflicts of Interest: None declared. 